\title{
Análise do crescimento de tomate 'SM-16' cultivado sob diferentes coberturas de solo
}

\author{
Welder de AR Lopes; Maria Zuleide de Negreiros; Jeferson Luiz D Dombroski; Gardênia Silvana de O \\ Rodrigues; Alinne M Soares; Antônio de P Araújo \\ UFERSA-Depto. Ciências Vegetais, C. Postal 137, 59625-900 Mossoró-RN; welder.lopes@hotmail.com; zuleide@ufersa.edu.br; \\ jeferson@ufersa.edu.br; gardeniavg@yahoo.com.br; alinne_menezes@hotmail.com; agropadua@yahoo.com.br
}

\section{RESUMO}

Com o objetivo de analisar o crescimento de plantas de tomate 'SM-16', cultivadas sob diferentes coberturas de solo conduziu-se um experimento na WG Fruticultura, Baraúna-RN entre julho e novembro de 2008. O delineamento experimental adotado foi o de blocos casualizados completos, com quatro repetições. Os tratamentos foram dispostos em parcelas subdivididas, sendo as parcelas representadas pelos tipos de cobertura de solo: solo descoberto, filme de polietileno preto, filme de polietileno prateado, filme de polietileno branco e polipropileno preto (TNT), e as sub-parcelas pelas épocas de amostragens das plantas: 14, 28, 42, 56, 70, 84 e 98 dias após o transplantio (DAT). Foram avaliados: acúmulo de massa seca nas folhas (AMSF), ramos (AMSR), inflorescências (AMSI), frutos (AMSFR) e total (AMST), índice de área foliar (IAF), razão de área foliar (RAF), área foliar específica (AFE), taxa de crescimento absoluto (TCA), taxa de crescimento relativo (TCR) e taxa assimilatória líquida (TAL). As coberturas de solo influenciaram o desenvolvimento do acúmulo de massa seca nas folhas, ramos e frutos, sendo o TNT a que promoveu as maiores médias. Os frutos se comportaram como dreno preferencial da planta. O TNT foi a cobertura de solo que promoveu as maiores médias para o índice de área foliar e as taxas de crescimento absoluto e relativo. A razão de área foliar, área foliar específica e taxa assimilatória líquida não foram influenciadas pelas coberturas de solo.

Palavras-chave: Lycopersicon esculentum, mulching, partição de assimilados, taxa de crescimento.

\begin{abstract}
Growth analysis of tomato plants 'SM-16' cultivated under different mulching

In order to evaluate the growth of tomato plants cv. SM-16, grown under different mulching, a trial was carried out at WG Fruticultura, Baraúna, Rio Grande do Norte state, Brazil, between July and November 2008. The experimental design was arranged in splitplots, under completely randomized blocks with four replications. Treatments (plots) were the mulching types: uncovered soil, black polyethylene film, silver polyethylene film, white polyethylene film and black polypropylene TNT, and the splitplots were sampling times: 14, 28, 42, 56, 70, 84 and 98 days after transplanting (DAT). Dry mass accumulation in leaves (AMSF), branches (AMSR), inflorescences (AMSI), fruits (AMSFR) and total (AMST), leaf area index (IAF), leaf area ratio (RAF), specific leaf area (AFE), absolute growth rate (TCA), relative growth rate (TCR) and net assimilation rate (TAL) were determined. The mulching influenced the development of dry matter accumulation in leaves, branches and fruits, and the TNT promoted the highest averages. The fruits behaved as the preferential drain of the plant. The TNT was the mulching that has promoted the highest average for the leaf area index and absolute and relative growth rates. The leaf area ratio, specific leaf area and net assimilation rate were not influenced by cover crops.
\end{abstract}

Keywords: Lycopersicon esculentum, mulching, assimilate partition, growth rate.

(Recebido para publicação em 6 de dezembro de 2010; aceito em 24 de novembro de 2011) (Received on December 6, 2010; accepted on November 24, 2011)

$\mathrm{O}$ crescimento e o rendimento final de uma cultivar ou outro material genético é o resultado de suas interações com o ambiente. Entretanto, para se compreender alguns aspectos da natureza dos controles intrínsecos de cada material, necessita-se do estabelecimento de índices mais detalhados que permitam uma melhor compreensão dessas interações, através da análise quantitativa do crescimento. Esta análise se fundamenta no desenvolvimento de testes e modelos de simulação do crescimento e produtividade da cultura, baseado em vários índices fisiológicos (Benincasa, 2003).

Os índices envolvidos, determinados na análise de crescimento, indicam a capacidade do sistema assimilatório das plantas em sintetizar e alocar a matéria orgânica nos diversos órgãos que dependem da fotossíntese, respiração e translocação de fotoassimilados dos sítios de fixação de carbono aos locais de utilização ou de armazenamento, onde ocorrem o crescimento e a diferenciação dos órgãos. Portanto, a análise de crescimento expressa as condições morfofisiológicas da planta e quantifica a produção líquida, derivada do processo fotossintético, sendo o resultado do desempenho do sistema assimilatório durante certo período de tempo. Esse desempenho é influenciado pelos fatores bióticos e abióticos à planta (Larcher, 2004).
Alguns trabalhos têm mostrado a importância do conhecimento acerca do crescimento e índices fisiológicos, bem como a influência de fatores externos sobre a produção final da planta (Peluzio et al., 1999; Fayad et al., 2001; Andriolo et al., 2004), entretanto não são comuns os estudos relacionados a este tema envolvendo a utilização de cobertura do solo no cultivo do tomate.

A utilização da cobertura do solo tornou-se importante e bastante difundida na produção de diversas espécies de hortaliças, constituindo-se, inclusive, em condição básica para que muitas delas apresentem produtos com qualidade aceitável, em níveis rentáveis de produtividade. Essa prática tem se mos- 
trado fator determinante no cultivo de hortaliças contribuindo para a melhoria da produção e qualidade dos produtos.

A cobertura mais comumente utilizada é o filme de polietileno, embora possam ser empregados materiais de origem vegetal como raspas de madeira, palha de carnaúba e palha de milho (Queiroga et al., 2002). A utilização de restos vegetais como cobertura morta do solo em culturas como a rúcula também é uma alternativa viável, pois proporciona aumento da produção (Solino et al., 2010).

Coberturas do solo com filmes de polietileno têm levado ao incremento em crescimento e produtividade em várias hortaliças (Chaves et al., 2004; Medeiros et al., 2006, Cantu et al., 2007; Morais et al., 2008) incluindo o tomateiro (Lamont Júnior, 1993; Souza, 2005). Conforme os autores, o aumento no crescimento e na produtividade é atribuído a modificações na temperatura do solo e do ar próximo à cobertura, balanço hídrico e disponibilidade de nutrientes.

Embora os filmes plásticos de polietileno sejam amplamente utilizados como mulching em diversas hortaliças, o tecido de polipropileno ou agrotêxtil (TNT) tem sido empregado como manta sobre as plantas de melão e melancia (Medeiros et al., 2007; Dantas et al., 2009) mas também, recentemente como cobertura do solo, proporcionando aumento de produção e diminuindo a incidência de plantas daninhas, em hortaliças como a alface (Reghin et al., 2002) e maior produtividade de frutos comerciais no cultivo do tomate (Factor et al., 2009).

Diante do exposto, objetivou-se com o presente trabalho, avaliar o comportamento de plantas de tomate 'SM-16', cultivadas sob diferentes coberturas de solo, através da análise do crescimento.

\section{MATERIAL E MÉTODOS}

O experimento foi instalado na $\mathrm{WG}$ Fruticultura, no município de Baraúna-RN (5'05'S, 37 $38^{\circ} \mathrm{W}, 95 \mathrm{~m}$ de altitude), entre julho e novembro de 2008, em Cambissolo Háplico de textura argilosa (Embrapa, 1999). O clima da região, se- gundo a classificação Köppen, é BSwh', isto é, seco e muito quente, com duas estações climáticas: uma seca, que vai, geralmente, de junho a janeiro, e uma chuvosa, de fevereiro a maio (Carmo Filho et al., 1991).

O delineamento experimental adotado foi de blocos casualizados completos, com quatro repetições. Os tratamentos foram dispostos em parcelas subdivididas, sendo as parcelas representadas pelos tipos de cobertura de solo: solo descoberto (testemunha), filme de polietileno preto, filme de polietileno prateado (dupla face preto e prateado), filme de polietileno branco (dupla face preto e branco) e o polipropileno preto (agrotêxtil ou TNT), e as subparcelas pelas épocas de amostragens das plantas: 14, 28, 42, 56, 70, 84 e 98 dias após o transplantio (DAT). Cada parcela foi composta por três fileiras de 28 plantas, considerando-se como útil a fileira central, excluindo-se as plantas das extremidades. O espaçamento empregado foi de 2,0 m entre fileiras e 0,50 $\mathrm{m}$ entre plantas, com área total e útil de 84 e $24 \mathrm{~m}^{2}$.

O híbrido SM-16 utilizado apresenta plantas vigorosas de crescimento determinado, bom pegamento de frutos, frutos tipo pêra (saladete) com peso de 180 a 220 g, ciclo médio de 105 a 115 dias (Seminis, 2011), alta produtividade e resistências a Verticillium albo-atrum e Verticillium dahliae (Raças 1 e 2), Meloidogyne incognita, Meloidogyne javanica, Meloidogyne arenaria e Fusarium. Este híbrido é o mais cultivado pelos produtores da região.

A semeadura foi realizada em bandejas de poliestireno expandido de 200 células, utilizando-se o substrato comercial Golden Mix ${ }^{\circledR}$. As mudas foram transplantadas no dia 25 de agosto de 2008, no estádio de quatro a seis folhas verdadeiras, 25 dias após a semeadura.

O preparo do solo constou de uma aração e gradagem, seguido do sulcamento em linhas, com profundidade de $20 \mathrm{~cm}$, onde foi realizada a adubação de plantio com $400 \mathrm{~kg} \mathrm{ha}^{-1}$ de fosfato monoamônico (MAP), com posterior fechamento dos sulcos.

Foi utilizada a irrigação por gotejamento, com fita flexível de $16 \mathrm{~mm}$ e vazão de $1,5 \mathrm{~L} \mathrm{~h}^{-1}$ por gotejador, para uma pressão de serviço de $100 \mathrm{KPa}$ e emissores espaçados de $30 \mathrm{~cm}$. Após a instalação do sistema de irrigação, foi feita a cobertura do solo com os filmes de polietileno e com o polipropileno nas fileiras de plantas. Posteriormente efetuou-se a abertura dos orifícios de plantio, distanciados $50 \mathrm{~cm}$, com um vazador de 2,5 polegadas de diâmetro.

As adubações em cobertura foram efetuadas diariamente via fertirrigação, obedecendo aos estádios de desenvolvimento da cultura, para tanto utilizou-se $225 \mathrm{~kg} \mathrm{ha}^{-1}$ de $\mathrm{N}, 125 \mathrm{~kg} \mathrm{ha}^{-1}$ de $\mathrm{P}_{2} \mathrm{O}_{5}$ e $390 \mathrm{~kg} \mathrm{ha}^{-1}$ de $\mathrm{K}_{2} \mathrm{O}$. As fontes de nitrogênio utilizadas foram $64,67 \%$ (uréia), 13,18\% (MAP), 18,51\% (nitrato de cálcio) e 3,64\% (ácido nítrico). Para o $\mathrm{P}_{2} \mathrm{O}_{5}$ e $\mathrm{K}_{2} \mathrm{O}$ as fontes utilizadas foram $100 \%$ de MAP e $100 \%$ cloreto de potássio, respectivamente.

As plantas foram conduzidas sem tutoramento e desbrota. O controle de doenças e pragas foi feito de acordo com as recomendações convencionais com aplicações de fungicidas e inseticidas conforme as necessidades da cultura. $\mathrm{O}$ controle de plantas daninhas foi realizado manualmente com enxadas nas parcelas sem cobertura e entre canteiros das parcelas com cobertura.

Para a análise do crescimento foram amostradas 02 (duas) plantas competitivas de tomate, no período da manhã, em intervalos de quatorze dias até os 98 dias após o transplantio (DAT). Após cada coleta, as plantas foram fracionadas em ramos, folhas, inflorescências e frutos, lavados e colocados em estufa com circulação forçada de ar, à temperatura de $65^{\circ} \mathrm{C}$ até atingir massa constante.

Foram avaliados o acúmulo de massa seca nas folhas (AMSF); nos ramos (AMSR); nas inflorescências (AMSI); nos frutos (AMSFR) e total (AMST), obtidos através de pesagens da matéria seca de cada órgão. Com base na área foliar e nas massas secas foram determinadas as seguintes características, de acordo com as sugestões de Benincasa (2003): Índice de área foliar (IAF): $\mathrm{IAF}=\mathrm{AF} / \mathrm{S}$, onde $\mathrm{AF}$ foi a área foliar e $\mathrm{S}$, o espaço disponível para a planta, neste caso considerou-se como espaço disponível 200 x $50 \mathrm{~cm}$; razão de área foliar: $\mathrm{RAF}=\mathrm{AF} / \mathrm{MST}\left(\mathrm{cm}^{2} / \mathrm{g}\right)$, onde $\mathrm{AF}$ foi a área foliar e MST, a massa 
seca total; área foliar específica: AFE $=\mathrm{AF} / \mathrm{MSF}$ olha $\left(\mathrm{cm}^{2} / \mathrm{g}\right)$, onde MSFolha foi a massa seca de folhas; taxa de crescimento absoluto: $\mathrm{TCA}=\left(\mathrm{P}_{2}-\mathrm{P}_{1}\right)$ / $\left(\mathrm{T}_{2}-\mathrm{T}_{1}\right)(\mathrm{g} / \mathrm{planta} / \mathrm{dia})$; taxa de crescimento relativo: TCR $=\left(\ln \left(\mathrm{P}_{2}\right)-\ln \left(\mathrm{P}_{1}\right)\right)$ ) $\left(\mathrm{T}_{2}-\mathrm{T}_{1}\right)(\mathrm{g} / \mathrm{g} / \mathrm{dia})$, onde $\ln \left(\mathrm{P}_{2}\right)$ e $\ln \left(\mathrm{P}_{1}\right)$ foram os logaritmos naturais das massas da matéria seca de duas amostragens sucessivas; taxa assimilatória líquida: $\mathrm{TAL}=\left[\left(\mathrm{P}_{2}-\mathrm{P}_{1}\right) /\left(\mathrm{T}_{2}-\mathrm{T}_{1}\right)\right] \times\left[\left(\ln \left(\mathrm{A}_{2}\right)-\right.\right.$ $\left.\left.\ln \left(A_{1}\right)\right) /\left(A_{2}-A_{1}\right)\right]\left(g / \mathrm{cm}^{2} / d i a\right)$. Para todas as equações, $\mathrm{P}_{2}$ e $\mathrm{P}_{1}$ foram as massas da matéria seca de duas amostragens sucessivas, $\mathrm{T}_{2}$ e $\mathrm{T}_{1}$ representaram as épocas de amostragem, neste caso, essa diferença de tempo foi fixada em 14 dias, e $\mathrm{A}_{2}$ e $\mathrm{A}_{1}$ representaram as áreas foliares de duas amostragens sucessivas.

Os dados foram submetidos às análises de variância, sendo as médias das coberturas comparadas pelo teste de Tukey a 5\% de probabilidade, através do software SAEG (Ribeiro Júnior, 2001), de regressão não-linear (logística) (Yin et al., 2003) utilizando-se o software SPSS 15 e de regressões polinomiais, obedecendo-se o nível de significância de $5 \%$ de probabilidade pelo teste $\mathrm{F}$, através do software Table Curve 2D v5.01 (Jandel Scientific, 1991).

\section{RESULTADOS E DISCUSSÃO}

Houve interação significativa entre as épocas de amostragem e coberturas de solo para o acúmulo de massa seca nas folhas (AMSF) que apresentou comportamento sigmóide, semelhante para todas as coberturas de solo, com crescimento lento até aproximadamente os 28 DAT, intensificando-se a partir de então e com tendência a estabilizar-se após os 70 DAT (Figura 1A). A estabilização no acúmulo de massa seca nas folhas ocorreu, possivelmente, em decorrência da fase da senescência se sobrepor à emissão de novas folhas. Esses dados corroboram com os obtidos por Chirinos-Torres et al. (1999), trabalhando com a cv. Rio Grande. Observando-se as coberturas dentro de cada época, verifica-se que dos 14 aos 56 DAT, não foram observadas diferenças significativas entre as coberturas empregadas. Aos 70 DAT, o solo descoberto promoveu maior AMSF, não diferindo estatisticamente do TNT, que por sua vez, não diferiu das coberturas de polietileno. Aos 84 DAT, o TNT e o solo descoberto promoveram maior AMSF, sendo superiores as coberturas de polietileno, que não diferiram entre si. Aos 98 DAT, o TNT foi responsável pelo maior AMSF, apesar de não diferir do solo descoberto e do filme de polietileno preto, estes, entretanto não diferiram dos filmes de polietileno branco e prateado que foram responsáveis pelas menores médias (Tabela 1).

Houve interação significativa entre as épocas de amostragem e coberturas de solo para o acúmulo de massa seca nos ramos (AMSR) que apresentou crescimento lento até os 28 DAT, para todas as coberturas de solo. A partir de então, verifica-se que ocorreu um crescimento mais intenso e tendência a estabilização a partir dos 70 DAT, para o solo descoberto e os filmes de polietileno branco, preto e prateado (Figura 1B). Comportamentos semelhantes foram observados por Fayad et al. (2001), tanto no cultivo em condições de campo (cv. Santa Clara) como em ambiente protegido (híbrido EF-50). Avaliando-se as coberturas dentro de cada época, verifica-se que até 56 DAT, não houve diferenças significativas entre os tratamentos empregados. Aos 70 DAT, o solo sem cobertura promoveu maior AMSR, não diferindo do filme de polietileno prateado e do TNT, que por sua vez, não diferiu dos filmes preto e branco. Aos 84 DAT, o solo sem cobertura foi responsável por maior AMSR, não diferindo significativamente dos filmes de polietileno branco e preto e do TNT preto, que também não diferiu do filme de polietileno prateado. Aos 98 DAT o TNT preto apresentou AMSR superior aos demais tratamentos, que não diferiram entre si (Tabela 1).

$\mathrm{O}$ acúmulo de massa seca nas inflorescências (AMSI) foi influenciado

Tabela 1. Valores médios do acúmulo de massa seca nas folhas (AMSF) e ramos (AMSR) de tomate 'SM-16' cultivado sob diferentes coberturas de solo (average values of dry matter accumulation in leaves (AMSF) and branches (AMSR) of tomato plants 'SM-16', cultivated under different mulching). Baraúna, UFERSA, 2008.

\begin{tabular}{|c|c|c|c|c|c|c|c|}
\hline \multirow{2}{*}{ Tipos de cobertura } & \multicolumn{7}{|c|}{ AMSF (g/planta) } \\
\hline & 14 DAT & 28 DAT & 42 DAT & 56 DAT & 70 DAT & 84 DAT & 98 DAT \\
\hline Sem cobertura & $1,88 a^{*}$ & $20,71 \mathrm{a}$ & $90,61 \mathrm{a}$ & $138,93 a$ & $234,85 \mathrm{a}$ & $201,30 \mathrm{a}$ & $191,14 \mathrm{ab}$ \\
\hline Polietileno preto & $1,08 \mathrm{a}$ & $16,67 \mathrm{a}$ & $66,12 \mathrm{a}$ & $138,73 \mathrm{a}$ & $164,11 b$ & $179,67 b$ & $199,73 \mathrm{ab}$ \\
\hline Polietileno prata & $1,29 \mathrm{a}$ & $16,74 a$ & $73,28 \mathrm{a}$ & $131,81 \mathrm{a}$ & $180,70 \mathrm{~b}$ & $162,82 b$ & $160,43 b$ \\
\hline Polietileno branco & $1,56 \mathrm{a}$ & $21,43 a$ & $88,94 \mathrm{a}$ & $162,24 \mathrm{a}$ & $169,55 b$ & $185,74 b$ & $171,66 b$ \\
\hline \multirow[t]{3}{*}{ TNT } & $1,37 \mathrm{a}$ & $21,16 \mathrm{a}$ & $75,16 \mathrm{a}$ & $152,06 \mathrm{a}$ & $187,53 \mathrm{ab}$ & $218,04 \mathrm{a}$ & $241,05 \mathrm{a}$ \\
\hline & \multicolumn{7}{|c|}{ AMSR (g/planta) } \\
\hline & 14 DAT & 28 DAT & 42 DAT & 56 DAT & 70 DAT & 84 DAT & 98 DAT \\
\hline Sem cobertura & $0,48 \mathrm{a}$ & $7,61 \mathrm{a}$ & $38,79 a$ & $62,05 \mathrm{a}$ & $103,49 a$ & $112,99 a$ & $96,37 b$ \\
\hline Polietileno preto & $0,37 \mathrm{a}$ & $6,31 \mathrm{a}$ & $32,47 \mathrm{a}$ & $68,07 \mathrm{a}$ & $77,82 \mathrm{~b}$ & $100,97 \mathrm{a}$ & $102,48 b$ \\
\hline Polietileno prata & $0,45 \mathrm{a}$ & $6,86 \mathrm{a}$ & $31,89 \mathrm{a}$ & $65,32 \mathrm{a}$ & $92,03 \mathrm{a}$ & $82,83 b$ & $81,56 b$ \\
\hline Polietileno branco & $0,45 \mathrm{a}$ & $8,65 \mathrm{a}$ & $41,66 \mathrm{a}$ & $77,42 \mathrm{a}$ & $77,17 \mathrm{~b}$ & $116,25 \mathrm{a}$ & $85,93 b$ \\
\hline TNT & $0,45 \mathrm{a}$ & $7,92 \mathrm{a}$ & $34,20 \mathrm{a}$ & $70,78 \mathrm{a}$ & $89,80 \mathrm{ab}$ & $97,90 \mathrm{ab}$ & $135,31 \mathrm{a}$ \\
\hline
\end{tabular}

*Médias na vertical seguidas pela mesma letra, para cada característica, não diferem entre si, pelo teste de Tukey a 5\% de probabilidade (means in vertical, followed by the same letter, for each feature, don't differ by Tukey test at 5\% probability). 
Tabela 2. Valores médios do acúmulo de massa seca total (AMST), nos frutos (AMSFR), índice de área foliar (IAF), taxa de crescimento absoluto (TCA) e taxa de crescimento relativo (TCR) de plantas de tomate 'SM-16' cultivado sob diferentes coberturas de solo (average values of total dry matter accumulation (AMST), fruits (AMSFR), leaf area index (IAF), absolute growth rate (TCA) and relative growth rate (TCR) of tomato plants 'SM-16', cultivated under different mulching). Baraúna, UFERSA, 2008.

\begin{tabular}{lccccc}
\hline Tipos de cobertura & $\begin{array}{c}\text { AMST } \\
\text { (g/planta) }\end{array}$ & $\begin{array}{c}\text { AMSFR } \\
\text { (g/planta) }\end{array}$ & IAF & $\begin{array}{c}\text { TCA } \\
\text { (g/planta/dia) }\end{array}$ & $\begin{array}{c}\text { TCR } \\
\text { (g/g/dia) }\end{array}$ \\
\hline Sem cobertura & $356,93 \mathrm{a}$ & $220,16 \mathrm{ab}$ & $2,5000 \mathrm{ab}$ & $6,8059 \mathrm{ab}$ & $0,0703 \mathrm{ab}$ \\
Polietileno preto & $308,88 \mathrm{a}$ & $182,62 \mathrm{~b}$ & $2,1500 \mathrm{ab}$ & $6,9134 \mathrm{ab}$ & $0,0703 \mathrm{ab}$ \\
Polietileno prata & $311,85 \mathrm{a}$ & $201,05 \mathrm{ab}$ & $1,8900 \mathrm{~b}$ & $6,3343 \mathrm{~b}$ & $0,0692 \mathrm{ab}$ \\
Polietileno branco & $333,03 \mathrm{a}$ & $204,95 \mathrm{ab}$ & $2,1400 \mathrm{ab}$ & $6,0690 \mathrm{~b}$ & $0,0687 \mathrm{~b}$ \\
TNT & $374,45 \mathrm{a}^{*}$ & $236,93 \mathrm{a}$ & $2,5800 \mathrm{a}$ & $8,7897 \mathrm{a}$ & $0,0728 \mathrm{a}$ \\
\hline
\end{tabular}

*Médias na vertical seguidas pela mesma letra, não diferem entre si, pelo teste de Tukey a 5\% de probabilidade (means in vertical, followed by the same letter, do not differ by Tukey test at $5 \%$ probability).

apenas pelas épocas de amostragem. O AMSI apresentou comportamento sigmóide, com crescimento mais intenso a partir dos 42 DAT, e tendência à estabilização a partir dos 84 DAT, atingindo o máximo de acúmulo aos 98 DAT (Figura 1C).

O acúmulo de massa seca nos frutos (AMSFR) foi influenciado pelas épocas de amostragem e coberturas de solo. $\mathrm{O}$ aumento no número e o desenvolvimento dos frutos produzidos proporcionaram incrementos no acúmulo de massa seca com a idade da planta. Ao entrar na fase reprodutiva, mais precisamente com o início da frutificação, verifica-se que houve um maior direcionamento de fotoassimilados para os frutos, sendo observado crescimento acelerado na massa seca dos mesmos desde os 42 DAT, até os 84 DAT, a partir de quando ocorreu um crescimento menos intenso, até os 98 DAT, época em que foi verificado o máximo de acúmulo de massa seca nos frutos (Figura 1D). Entre as coberturas de solo, o TNT, foi o que proporcionou maior acúmulo de massa seca nos frutos, com uma média, ao longo do ciclo, de $236,93 \mathrm{~g} /$ planta, porém não diferindo do solo sem cobertura (220,15 g/planta) e dos filmes de polietileno branco $(204,95$ $\mathrm{g} /$ planta) e prateado (201,05 g/planta) (Tabela 2). Factor et al. (2009) verificaram que as coberturas do solo com polipropileno e com polietileno preto proporcionaram maiores produções de frutos de tomate do que o produzido no solo sem cobertura.

O acúmulo de massa seca total (AMST) foi influenciado pelas épocas de amostragem. O AMST foi lento aos primeiros $28 \mathrm{DAT}$, aumentando a partir desta época, com o ingresso da planta na fase reprodutiva, e intensificando no período de 42 aos 84 DAT. O máximo acúmulo foi verificado aos 98 DAT, com média de 684,96 g/planta (Figura 1E). Chirinos-Torres et al. (1999) verificaram que o padrão de crescimento da planta de tomate cv. Río Grande seguiu uma curva sigmóide simples, com máximo acúmulo aos 90 DAT. Não foram verificadas diferenças entre as coberturas de solo, pelo teste de Tukey, para o AMST (Tabela 2).

A distribuição de assimilados nos diferentes órgãos das plantas de tomate seguiu o mesmo padrão, para todas as coberturas de solo. No início do ciclo, aos 14 DAT, as folhas se comportam como fonte-dreno, uma vez que são as responsáveis pela produção de fotoassimilados, e também o órgão com maior armazenamento, acumulando $76,3 \%$ da massa seca total da planta. Nesta mesma época os ramos se comportaram como dreno, mantendo-se desta forma até o final do ciclo. Com o início da frutificação, o direcionamento dos assimilados das folhas para os frutos ocorre de forma intensa. Ramos, inflorescências e frutos se comportam como dreno, entretanto os frutos são o dreno preferencial da planta e chegam ao final do ciclo com $52,5 \%$, enquanto as folhas representam apenas $28,5 \%$, ramos $14,8 \%$ e inflorescências 4,3\% da massa seca acumulada (Figura 1F). Fayad et al. (2001) também verificaram que os frutos são o dreno preferencial da planta.

O IAF é a relação entre a área foliar e a área do solo sombreada pelas folhas.
Assim à medida que a área foliar cresce o IAF também cresce, até que o auto-sombreamento passa a ser prejudicial diminuindo a eficiência fotossintética (Benincasa, 2003).

O IAF aumentou até 74 DAT, quando atingiu o valor de 4,05. A partir desta época houve decréscimo, chegando aos 98 DAT, com média de 2,77 (Figura 2A). A queda no IAF indica senescência e abscisão foliar. Heuvelink (1995) encontrou IAF 3,0 ao final do ciclo do tomateiro. Fayad et al. (2001) verificaram que o IAF do tomate cv. Santa Clara atingiu o valor máximo, de 4,12 aos 58 dias, chegando ao final do ciclo com 0,17 .

Com relação às coberturas de solo, o TNT preto foi o que promoveu maior média de IAF, ao longo do ciclo, 2,58, não diferindo significativamente do solo sem cobertura $(2,50)$, filmes de polietileno preto $(2,15)$ e branco $(2,14)$, e estes, não diferiram do filme de polietileno prateado, que promoveu, ao longo do ciclo da cultura, a menor média do índice de área foliar $(1,89)$ (Tabela 2).

Verificou-se comportamento linear decrescente dos $14\left(173,99 \mathrm{~cm}^{2} / \mathrm{g}\right)$ aos 98 DAT $\left(34,60 \mathrm{~cm}^{2} / \mathrm{g}\right)$ para a razão de área foliar (Figura 2B). A análise da RAF nos permite detectar a translocação e partição de assimilados para as folhas em relação à matéria seca da planta toda. O seu decréscimo indica que progressivamente a quantidade de assimilados destinados às folhas é diminuída, em função do desenvolvimento das estruturas de sustentação e reprodutivas em detrimento do investimento em área foliar. Peluzio et al. (1999) afirmam 


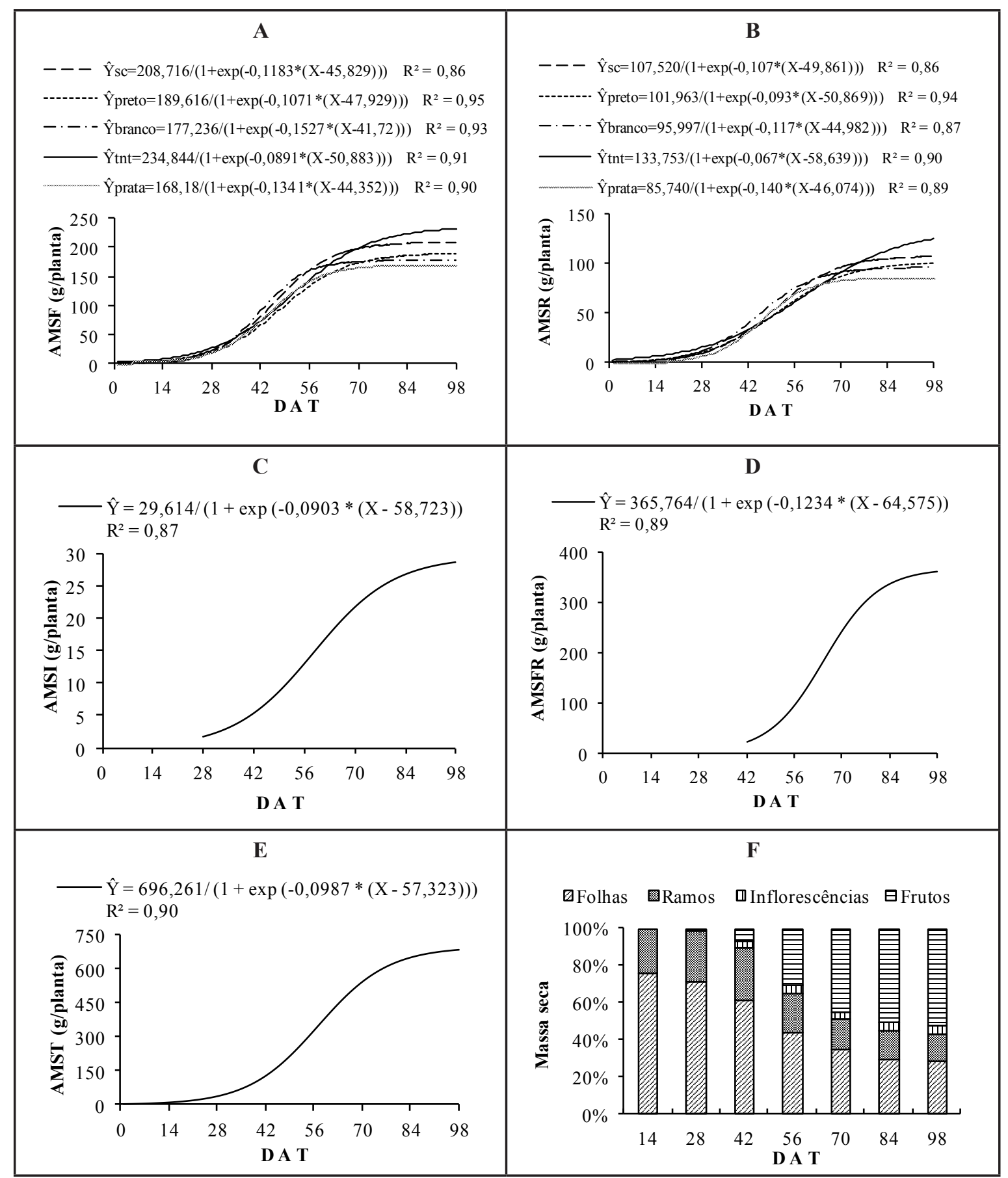

Figura 1. Acúmulo de massa seca nas folhas (A), ramos (B), inflorescências (C), frutos (D) e total (E) e partição de assimilados (F) de tomate 'SM-16' cultivado sob diferentes coberturas de solo (dry matter accumulation in leaves (A), branches (B), inflorescences (C), fruits (D) and total (E) and assimilate partition (F) of tomato plants 'SM-16', cultivated under different mulching). Baraúna, UFERSA, 2008.

que a RAF apresenta decréscimo com a ontogenia da planta. No cultivo do pimentão, Silva et al. (2010) verificaram que a RAF decresceu em função da idade da planta, resultado também descrito por Fontes et al. (2005).

A AFE apresentou comportamento quadrático atingindo o valor máximo estimado de $230,21 \mathrm{~cm}^{2} / \mathrm{g}$ aos 40 DAT. A partir desta data AFE decresceu até o final do período de avaliação, 98 DAT, registrando $145,95 \mathrm{~cm}^{2} / \mathrm{g}$ (Figura $2 \mathrm{C}$ ). $O$ decréscimo na AFE indicou que houve aumento da biomassa nas folhas e redução da expansão foliar. Fayad et al. (2001) e Heuvelink (1995) encontraram comportamentos semelhantes, trabalhando com tomate híbrido EF-50 e cv. Counter, respectivamente, entretanto foi verificado em ambos os casos, crescimento até 30 DAT com posterior decréscimo ao longo do ciclo.

A taxa assimilatória líquida aumentou até 28 DAT, decrescendo com a idade da planta, a partir desta época (Figura 2D). Pode-se afirmar que a partir dos 28 DAT, com o aumento do crescimento da planta, inclusive da área foliar, iniciou-se um auto-sombreamento das folhas, o que levou à diminuição dos níveis de 


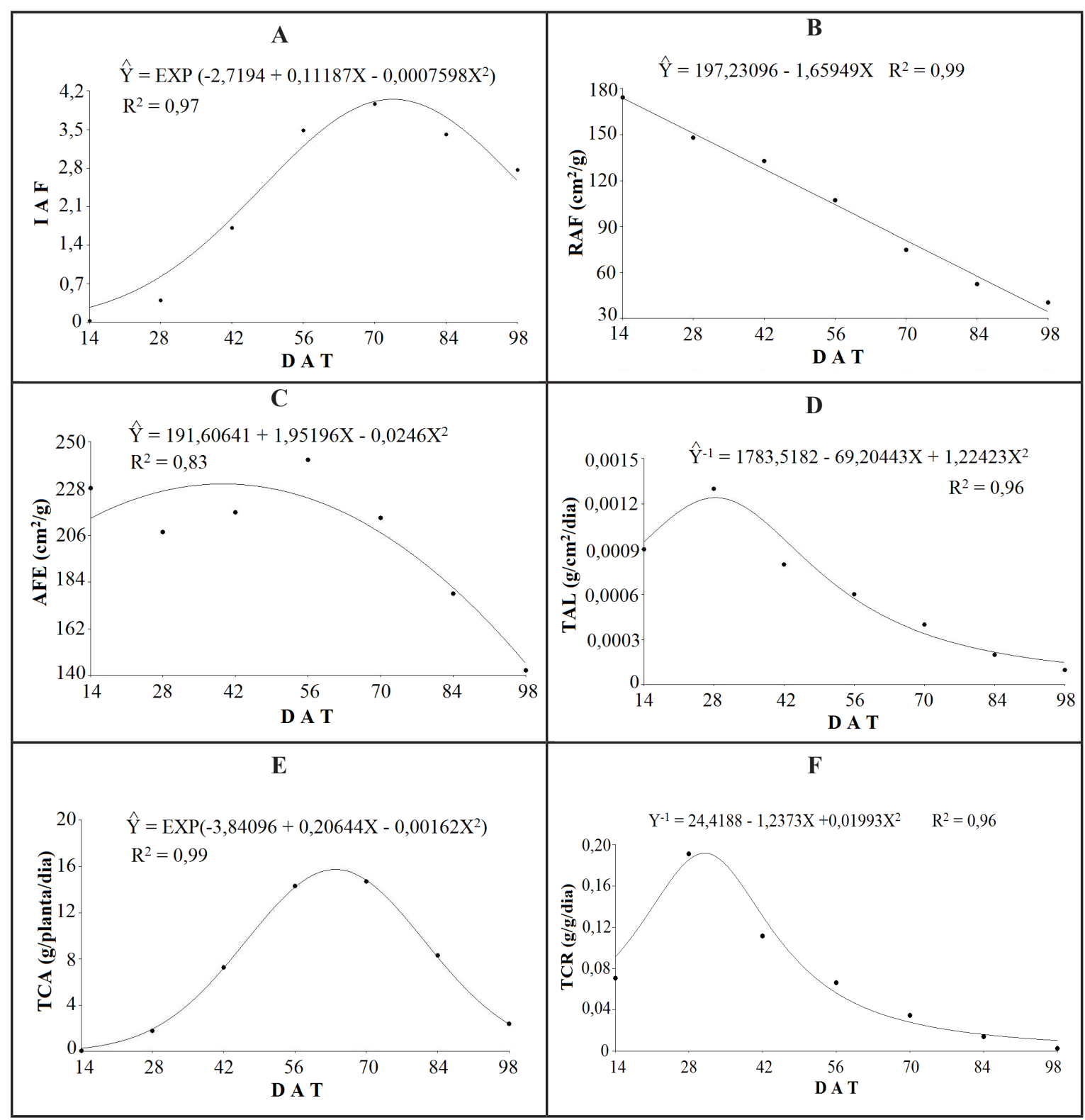

Figura 2. Índice de área foliar (A), razão de área foliar (B), área foliar específica (C), taxa assimilatória líquida (D), taxa de crescimento absoluto (E) e taxa de crescimento relativo (F) de plantas de tomate 'SM-16' cultivado sob diferentes coberturas de solo (leaf area index (A), leaf area ratio (B), specific leaf area (C), net assimilation rate (D), absolute growth rate (E) and relative growth rate (F) of tomato plants 'SM-16', cultivated under different mulching). Baraúna, UFERSA, 2008.

fotossíntese líquida, ou seja, redução na TAL.

Comportamentos diferentes podem ser observados na TAL do tomateiro, variando de acordo com o material estudado, tipo de hábito de crescimento, práticas culturais empregadas, entre outros. Avaliando a cv. Santa Clara, Fayad et al. (2001) verificaram que a TAL foi crescente até 45 DAT, apresentando decréscimo a partir desta época. Porém avaliando o híbrido EF-50, os mesmos autores verificaram que a TAL declinou durante o ciclo da cultura. Peluzio et al. (1999) verificaram aumento gradativo até 69 DAT, com posterior decréscimo. Fontes et al. (2005) verificaram que a TAL do pimentão atingiu o valor máximo aos 56 DAT, declinando posteriormente até os $224 \mathrm{DAT}$, enquanto Silva et al. (2010) verificaram declínio durante todo o ciclo.

A taxa de crescimento absoluto apresentou comportamento quadrático, com crescimento máximo estimado de $15,75 \mathrm{~g} / \mathrm{planta} /$ dia obtido aos 64 DAT.
A partir desta época, houve decréscimo nesta taxa, atingindo ao final do período de avaliação a média de $2,39 \mathrm{~g} / \mathrm{planta} /$ dia (Figura 2E). A TCA cresceu com o aumento da área foliar, até a época em que o auto-sombreamento das folhas provocou o seu declínio. Fayad et al. (2001) verificaram que a taxa de crescimento absoluto cresceu até os 45 DAT, decrescendo a partir desta época, para o tomate cv. Santa Clara, já no tomate EF-50, ocorreu crescimento até 75 DAT e posterior decréscimo, até o 
final do ciclo.

No cultivo do pimentão é comum verificar que a TCA cresce durante todo o ciclo. Fontes et al. (2005) verificaram que houve crescimento contínuo até 224 DAT, época em que a TCA atingiu o valor de 2,26 g/planta/dia. Charlo et al. (2007) verificaram que o máximo de TCA ocorreu aos 168 DAT, com média de 4,47 g/planta/dia, enquanto Silva et al. (2010) descrevem que a TCA atingiu o máximo no final do período de avaliação, aos 126 DAT.

Entre as coberturas de solo empregadas, o TNT promoveu maior média de TCA (8,78 g/planta/dia), ao longo do ciclo, não diferindo do solo sem cobertura $(6,8059 \mathrm{~g} / \mathrm{planta} /$ dia $)$ e do filme de polietileno preto $(6,9134 \mathrm{~g} /$ planta/ dia), e estes, não diferiram dos filmes prateado e branco que foram responsáveis pelas menores médias (Tabela 2). Como a TCA representa a velocidade de crescimento da planta, e o TNT foi responsável pelas maiores médias de área foliar e acúmulo de massa seca nas folhas, e as folhas são os órgãos fotossintetizadores, é compreensível, que o uso do TNT como cobertura do solo tenha proporcionado também a maior taxa de crescimento absoluto.

A taxa de crescimento relativo apresentou crescimento máximo aos 31 DAT, declinando posteriormente até o final do período de avaliação da cultura (Figura 2F). Pode-se definir a TCR como o produto entre a taxa assimilatória líquida e a razão de área foliar (Benincasa, 2003). Assim o aumento da TCR até 31 DAT, deveu-se ao aumento na taxa assimilatória líquida, e sua redução, à diminuição contínua da razão de área foliar e posterior decréscimo da taxa assimilatória líquida.

Decréscimos nos valores de TCR ao longo do ciclo são comuns para a maioria das espécies, inclusive para o tomate, estando relacionados aos decréscimos na taxa assimilatória líquida (TAL) e na razão de área foliar (RAF). Com o aumento da massa acumulada pela planta, ocorre aumento da necessidade de fotoassimilados para a manutenção dos órgãos já formados. Assim, a quantidade de fotoassimilados disponível para o crescimento (TCR) tende a ser menor (Benincasa, 2003).
Estes resultados estão de acordo com os obtidos por Peluzio et al. (1999), no entanto, os autores verificaram que a TCR aumentou até 65 DAT, declinando posteriormente. Fayad et al (2001) verificaram que houve redução da TCR durante todo o ciclo da cultura, tanto para o tomate cv. Santa Clara, como para o híbrido EF-50. Em trabalhos realizados com pimentão, diversos autores afirmaram que a TCR decresceu durante todo o ciclo (Fontes et al., 2005; Charlo et al., 2007; Silva et al., 2010).

Entre as coberturas de solo utilizadas, verifica-se que o TNT foi o que promoveu maior média de TCR ao longo do ciclo, apesar de não apresentar diferença do solo sem cobertura e dos filmes de polietileno preto e prateado. Estes últimos, entretanto, não diferiram do filme de polietileno branco, que foi responsável pela menor média na taxa de crescimento relativo (Tabela 2).

Por meio dos resultados obtidos, constatou-se que as coberturas de solo influenciaram o desenvolvimento do acúmulo de massa seca nas folhas, ramos e frutos, sendo o TNT a que promoveu as maiores médias. Os frutos comportaram-se como dreno preferencial da planta. O TNT foi a cobertura de solo que promoveu as maiores médias para o índice de área foliar e as taxas de crescimento absoluto e relativo. A razão de área foliar, área foliar específica e taxa assimilatória líquida não foram influenciadas pelas coberturas de solo.

\section{AGRADECIMENTOS}

Os autores agradecem ao CNPq pelo auxílio financeiro à pesquisa e concessão de bolsa de mestrado ao primeiro autor, e a WG Fruticultura pelo apoio logístico.

\section{REFERÊNCIAS}

ANDRIOLO JL; ESPINDOLA MCG; GODOI R; BORTOLOTTO OC; LUZ GL. 2004. Crescimento e produtividade de plantas de tomateiro em cultivo protegido sob alta densidade e desfolhamento. Ciência Rural 34: 1251-1253.

BENINCASA MMP. 2003. Análise de crescimento de plantas: noções básicas. Jaboticabal: FUNEP. $42 \mathrm{p}$.

CANTU RR; JUNGLAUS RW; FERNANDES
LJC; GOTO R. 2007. Cultivo de rúcula em túneis com diferentes tipos de cobertura e mulching. Horticultura Brasileira 25: Suplemento. CD-ROM.

CARMO FILHO F; ESPÍNOLA SOBRINHO J; MAIA NETO JM. 1991. Dados climatológicos de Mossoró: um município semi-árido nordestino. Mossoró: ESAM, 121p.

CHARLO HCO; VARGAS PF; CASTOLDI R; OLIVEIRA SF; BRAZ LT. 2007. Análise de crescimento, partição de matéria seca e produção da cultura do pimentão cultivado em fibra de coco com fertirrigação. Horticultura Brasileira 25: Suplemento. CR-ROM.

CHAVES SWP; MEDEIROS JF; NEGREIROS MZ; SILVA AKM; FREITAS KKC. 2004. Rendimento de alface em função da cobertura do solo e freqüência de irrigação. Revista Caatinga 17: 25-31.

CHIRINO-TORRES D; CHIRINOS-TORRES L; MARÍN M; ROMÁN-URBINAZ.; VIELMABAPTISTA J; CASTRO C. 1999. Dinámica de acumulación de materia seca em la planta de tomate (Lycopersicon esculentum Miller), cv. Río Grande, en la zona noroccidental del estado Zulia, Venezuela. Rev. Fac. Agron. 16: 141-151.

DANTAS MSM; GRANGEIRO LC; MEDEIROS JF; CRUZ CA; CUNHA APA; MASRUA CP; MARROCOS STP. 2009. Rendimento e qualidade de frutos de melancia cultivada sob proteção de agrotêxtil combinado com mulching plástico. Horticultura Brasileira 27: Suplemento. CD-ROM.

EMBRAPA - EMPRESA BRASILEIRA DE PESQUISAAGROPECUÁRIA. 1999. Centro Nacional de pesquisa do solo. Sistema brasileiro de classificação de solos. Rio de Janeiro: Serviço de produção de informação. 412p.

FACTOR TL; LIMA JÚNIOR S; PURQUEIRO LFV; BRANCO RF; BLAT SF; ARAÚJO JAC. 2009. Produtividade e qualidade de tomate em função da cobertura do solo e planta com agrotêxtil. Horticultura Brasileira 27: Suplemento. CD-ROM.

FAYAD JA; FONTES PCR; CARDOSO AA; FINGER LF; FERREIRA FA. 2001. Crescimento e produção do tomateiro cultivado sob condições de campo e de ambiente protegido. Horticultura brasileira 19: 232-237.

FONTES PCR; DIAS EN; SILVA DJH. 2005. Dinâmica do crescimento, distribuição de matéria seca e produção de pimentão em ambiente protegido. Horticultura Brasileira 23: 94-99.

HEUVELINK E. 1995. Growth, development and yield of a tomato crop: periodic destructive measurements in greenhouse. Scientia Horticulturae 61: 77-99.

JANDEL SCIENTIFIC. 1991. Table Curve: curve fitting software. Corte Madera, CA: Jandel Scientific. 280p.

LAMONT JUNIOR WJ. 1993. Plastic mulches for the production of vegetable crops. Hort Technology 3: 35-39.

LARCHER W. 2004. Ecofisiologia vegetal. São Carlos, SP: RiMa.. 531p.

MEDEIROS JF; SILVA MCC; CÂMARA 
NETO FG; ALMEIDA AHB; SOUZA JO; NEGREIROS MZ; SOARES SPF. 2006. Crescimento e produção do melão cultivado sob cobertura de solo e diferentes freqüências de irrigação. R. Bras. Eng. Agríc. Ambiental 10: 792-797.

MEDEIROS JF; SANTOS SCL; CÂMARA MJT; NEGREIROS MZ. 2007. Produção de melão Cantaloupe influenciado por coberturas do solo, agrotêxtil e lâminas de irrigação. Horticultura Brasileira 25: 538-543.

MORAIS ERC; MAIA CE; NEGREIROS MZ; ARAÚJO JÚNIOR BB; MEDEIROS JF. 2008. Crescimento e produtividade do meloeiro Goldex influenciado pela cobertura do solo. Scientia Agrária 9: 129-137.

PELUZIO JM; CASALI VWD; LOPES NF; MIRANDA GV; SANTOS GR. 1999. Comportamento da fonte e do dreno em tomateiro após a poda apical acima do quarto cacho. Ciência e Agrotecnologia 23: 510-514.

QUEIROGA RCF; NOGUEIRA ICC; BEZERRA NETO F; MOURA ARB; PEDROSA JF. 2002. Utilização de diferentes materiais como cobertura morta do solo no cultivo do pimentão. Horticultura Brasileira, 20: 416-418.

REGHIN MY; PURISSIMO C; FELTRIM AL; FOLTRAN MA. 2002. Produção de alface utilizando cobertura do solo e proteção de plantas. Scientia Agrária 3: 69-77.

RIBEIRO JÚNIOR JI. 2001. Análises estatísticas no SAEG. Viçosa: UFV. 301p.

SEMINIS - Seminis Vegetable Seeds, Inc. 2011. Disponível em: <http://www.seminis.com. br/products/tomate/sm_16.asp> Acesso em: 31 mai. 2011.

SILVA PIB; NEGREIROS MZ; MOURA KKCF;
FREITAS FCL; NUNES GHS; SILVA PSL; GRANGEIRO LC. 2010. Crescimento de pimentão em diferentes arranjos espaciais. Pesq. Agropec. Bras. 45: 132-139.

SOLINO AJS; FERREIRA RO; FERREIRA RLF; ARAÚJO NETO SE; NEGREIRO JRS. 2010. Cultivo orgânico de rúcula em plantio direto sob diferentes tipos de coberturas e doses de composto. Revista Caatinga, 23: 18-24.

SOUZA JG. 2005. Adensamento de plantas e altura de poda apical associados ao cultivo de cobertura plástica do solo, no cultivo do tomateiro. Ilha Solteira, SP: Universidade Estadual Paulista. 43p (Dissertação mestrado).

YIN X; GOUDRIAAN J; LANTINGA EA; VOS J; SPIERTZ J. 2003. A flexible sigmoid function of the determinate growth. Annals of Botany 91: 361-371. 